\title{
Possibility of the Benzoic Acids Formation by Oxidation of Benzyl Chlorides in the Sand
}

\author{
_First Example of Organic Halides Oxidation in Polluted Soil
}

\section{Masakazu Yamashita, Masato Hata}

Department of Environmental Systems Science, Doshisha University, Kyoto, Japan.

Email: myamashi@mail.doshisha.ac.jp

Received November $2^{\text {nd }}, 2012$; revised December $7^{\text {th }}$, 2012; accepted January $3^{\text {rd }}, 2013$

\begin{abstract}
Seeking the possibility of the formation of benzoic acids from benzyl halides in natural soil, a model oxidation reaction of the halides was carried out in the presence of water and soil in an open air under UV light irradiation. Addition of $\mathrm{TiO}_{2}$ to soil raised the yield of the acid, implying such a metal oxide plays a real catalytic role in this oxidation. By these supplementary experiments, one of the possibilities for the formation of benzoic acids in natural soil from benzyl chlorides was supported.
\end{abstract}

Keywords: Oxidation; Benzyl halides; Aromatic Carboxylic Acids

\section{Introduction}

The problem caused by toxic organic compounds, which were artificially discharged into the natural soil, air and water, is one of the numerous environmental issues. This issue has been sensationally reported as a problem related to endocrine-disturbing chemicals, so-called environmental hormones, but this still remains being unresolved, and extensive research activities are underway, seeking effective solutions [1]. It is even said that chemical substances existing in a trace amount in the natural environment could have such serious effects which even threaten the existence of living things. Therefore, when they are found in nature, we should swiftly identify their sources and prevent the causal material from being discharged into nature.

On the other hand, it is well-known that chemical substances discharged from an outlet are chemically transformed to other compounds in nature. This would occur especially with organic compounds at a relatively high probability. Since still a lot of things are left unresolved about how chemical compounds are transformed in the environment, possible reaction pathways should be examined and elucidated. Once a compound enters the natural environment, it is exposed to oxygen in the air, water or moisture, various metals in the soil, with the sunlight beating down on it simultaneously. Under these circumstances, a variety of possible oxidation reactions can be considered to occur. Therefore, we should conduct a model experiment for each compound in the laboratory and examine the probability of every possible reaction in advance.

By the way, a trace amount of aromatic carboxylic acids can sometimes be detected when soil components are analyzed [2]. In some cases, it is hard to consider that carboxylic acids themselves were directly dumped into the soil. And we cannot help but suspect that some other compounds were initially discharged, and then, some of which were changed to aromatic carboxylic acids. In our studies, aromatic halogenides are sometimes suspected to have been discharged in the natural soil.

In this study, we investigated the possibility of the formation of a carboxyl group from a chlorinated alkyl group, especially benzoic acid from benzyl chloride in the presence of soil. In some cases, titanium dioxide was employed as an additive, because it is one of the wellknown minerals which occurs in nature and is also the most widely used white pigment, so it is highly suspected that natural soil everywhere is contaminated artificially with this oxide. Besides, $\mathrm{PtO}_{2}$ is a well-known photocatalyst which oxidizes volatile organic compounds into carbon dioxide, and so on.

In this paper, the possibility for the formation of benzoic acids in natural soil from benzyl chlorides was confirmed by this supplementary experiment.

\section{Experimental}

\subsection{General}

Reaction products were analyzed with GC-14A gas 
chromatography (Shimadzu capillary column (CBP1W12-100, 0.53 m i.d. $\times 12 \mathrm{~m})$ ). The GC yields were measured using biphenyl as an internal standard. Commercially available benzyl chloride was distilled and purified under a nitrogen atmosphere before use. Commercial titanium oxide in an anatase form was employed. An ultraviolet lamp (Ultraviolet; UVGL-58 (254 nm)) was used for ultraviolet irradiation. A filter holder (HARIO Glass; FS-100) and a millipore filter (JGWP02500, 0.2 $\mu \mathrm{m})$ were employed for the filtration of titanium dioxide. Soil was collected at the athletic field of Doshisha University, Kyotanabe Campus, and washed by water three times before use.

\subsection{Reaction Procedure}

The typical reaction procedure was as follows. To a reaction bath (7.5-cm diameter) with a magnet stirrer, $50 \mathrm{ml}$ of distilled water and $30 \mathrm{~g}$ of washed soil were poured, and then benzyl chloride $(0.2 \mathrm{ml}, 1.74 \mathrm{mmol})$ was added at $20 \mathrm{C}$. While stirring the reaction mixture in open air, ultraviolet light (254 nm) was irradiated on it for $72 \mathrm{hr}$ from $7 \mathrm{~cm}$ above. Then, the organic layer of the reaction mixture was extracted with diethyl ether and the organic layer was filtered to remove residues. The filtrate was dried with anhydrous magnesium sulfate, filtered, and concentrated. The starting material, benzyl chloride, was evaporated by Kugelrohr distillation under a vacuum and the residue was purified by recrystallization to yield benzoic acid as a white solid (mp. $121.5 \mathrm{C}$ - $122.0 \mathrm{C}$ ). In case of using titanium dioxide, fixed amounts were added to the mixture of water and soil before the addition of benzyl chloride.

\section{Results and Discussion}

Oxidation reaction of benzyl chloride $\mathbf{1}$ with soil under ultraviolet irradiation is as follows (Scheme 1). As shown in Table 1, when reaction time was within 7 days, no benzoic acid 2 was obtained. However, a small amount of 2 was detected after 10 days irradiation and the yield reached to $3.2 \%$ after 20 days irradiation.

These results show that $\mathbf{1}$ can be oxidized to $\mathbf{2}$ in the polluted soil.

Table 1. Oxidation of benzyl chloride with soil.

\begin{tabular}{cc}
\hline Reaction time (day) & Yield $^{\mathrm{a})}$ of $2(\%)$ \\
\hline 3 & $\mathrm{Nd}^{\mathrm{b})}$ \\
7 & $\mathrm{Nd}^{\mathrm{b})}$ \\
10 & trace \\
20 & 3.3
\end{tabular}

a) Yields were determined by GC area using internal standards; ${ }^{\text {b) Not de- }}$ tected.<smiles>ClCc1ccccc1</smiles>

1

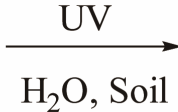

Scheme 1
When gathered soil was contaminated with white pigment which was used to mark the white lines of the ground, better yields of 2 were obtained. Therefore, we tried to examine the effect of titanium dioxide addition to the soil, because $\mathrm{TiO}_{2}$ is also one of the well-known minerals which occurs in nature and is the most widely used white pigment. For example, it is used to mark the white lines on the tennis courts of the All England Tennis and Croquet Club, Wimbledon [3]. Besides, $\mathrm{TiO}_{2}$ is a well-known photo-catalyst which oxidizes volatile organic compounds into carbon dioxide, and so on [4-6].

At first, the reaction was carried out with addition of $10 \mathrm{mg}$ of titanium dioxide and UV-irradiation for $2 \mathrm{hr}$, but the reaction did not proceed and no benzoic acid was obtained, leaving benzyl chloride unreacted. So, the amount of $\mathrm{TiO}_{2}$ was increased to 50, 100, and $200 \mathrm{mg}$, respectively. As shown in Table 2, 3.2\% yield of benzoic acid was obtained when $200 \mathrm{mg}$ of $\mathrm{TiO}_{2}$ was added to 30 $\mathrm{g}$ of soil.

Then, in order to raise the yield of $\mathbf{2}$, the UV-irradiation time was prolonged to 3, 5, 7, and 10 days. The results are shown in Table 3.

The reaction of benzyl chlorides other than 1 was also examined. For example, 1,4-bis(chloromethyl)benzene $\mathbf{3}$ was oxidized with the same reaction conditions and the corresponding terephthalic acid $\mathbf{4}$ was found to be produced in $12.3 \%$ yield (Scheme 2).

A plausible reaction mechanism, accepted generally in this field, is considered as follows [5] (Scheme 3).

Metal oxide in soil or $\mathrm{TiO}_{2}$ absorbs ultraviolet light to generate an electron and an electron hole. Then, the electron hole reacts with adsorbed water to generate a hydroxy radical. First, this hydroxy radical is attached to benzyl chloride $\mathbf{1}$. Then, after replacement of chlorine by $\mathrm{OH}$, benzyl radical $\mathbf{5}$ is generated. Compound $\mathbf{5}$ reacts with oxygen in air to generate a peroxy radical $\mathbf{6}$. Subsequently, an oxygen atom and a hydroxyl group are eliminated from 6 as a peroxy radical to generate benzaldehyde 7 , which can be easily oxidized to benzoiku acid 2 .

\section{Conclusion}

A possibility of the formation of benzoic acids from benzyl chlorides in polluted soil was confirmed. The truly active compounds in soil are considered to be metal oxides including $\mathrm{TiO}_{2}$. Thus, the possibility of the oxidation of benzylic halides to carboxylic acids in the natural 
<smiles>Cc1ccc(CCl)cc1</smiles>

3

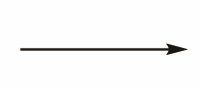

Scheme 2 $\underset{ }{\square}-\mathrm{CH}_{2} \mathrm{Cl}+\cdot \mathrm{OH} \longrightarrow$ 1<smiles>O=C(O)c1ccc(C(=O)O)cc1</smiles>

4<smiles>OCc1ccccc1</smiles>

5

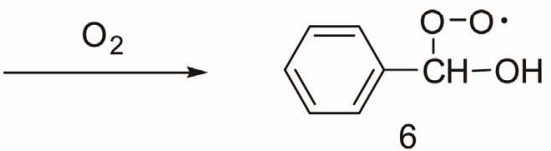

6

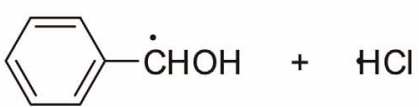

5<smiles>[O-]OC(O)c1ccccc1</smiles>

6

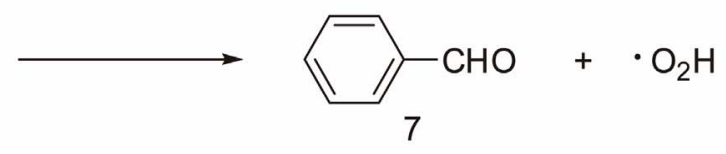

Scheme 3
Table 2. Formation of benzoic acid in soil with added $\mathrm{TiO}_{2}$.

\begin{tabular}{ccc}
\hline Added $\mathrm{TiO}_{2}(\mathrm{mg})$ & Time (hr) & Yield ${ }^{\mathrm{a})}(\%)$ \\
\hline 50 & 24 & 3.2 \\
100 & 24 & 14.1 \\
200 & 24 & 15.6 \\
\hline
\end{tabular}

a) Yields were determined by GC area using internal standards.

Table 3. Effect of irradiation time.

\begin{tabular}{ccc}
\hline TiO2 added (mg) & Reaction Time (day) & Yield $^{\text {a) }}(\%)$ \\
\hline 200 & 3 & 18.0 \\
200 & 5 & 19.5 \\
200 & 7 & 19.6 \\
200 & 10 & 20.2 \\
\hline
\end{tabular}

${ }^{a)}$ Yields were determined by GC area using internal standards.

environment was supported by this model-based experiment.

\section{REFERENCES}

[1] S. D. Coster and N. van Larebeke, "Endocrine-Disturbing Chemicals: Associated Disorders and Mechanisms of Ac- tion,” Journal of Environmental and Public Health, Vol. 2012, 2012, pp. 1-52,

[2] K. Fischer, "Environmental Analysis of Aliphatic Carboxylic Acids by Ion-Exclusion Chromatography," Analytica Chimica Acta, Vol. 465, No. 1-2, 2002, pp. 157173.

[3] S. Fujiwara, M. Kunugi and H. Shimizu, "Titanium Oxide,” In: Encyclopedia Chimica Editorial Committee, Ed., Encyclopedia Chimica, Vol. 3, Kyoritsu Shuppan, Tokyo, 1989, p. 920.

[4] D. Klauson, E. Portjanskaja and S. Preis, "Visible LightAssisted Photocatalytic Oxidation of Organic Pollutants Using Nitrogen-Doped Titania,” Environmental Chemistry Letters, Vol. 6, No. 1, 2008, pp. 35-39. doi:10.1007/s10311-007-0109-y

[5] I. H. Cho, H. Y. Kim and K. D. Zoh, "Detoxification of Trichloroethylene(TCE) Using Solar Light/ $\mathrm{TiO}_{2}$ in a UV Concentrating Radiation System," Journal of Water and Environmental Technology, Vol. 1, No. 1, 2003, pp. 37-42. doi:10.2965/jwet.2003.37

[6] T. Oyama, M. Takeuchi, I. Yanagisawa, T. Koike, N. Serpone and H. Hidaka, "Sunlight Photo-Assisted $\mathrm{TiO}_{2}$ Based Pilot Plant Scale Remediation of (Simulated) Contaminated Aquatic Sites,” Journal of Oleo Science, Vol. 59, No. 12, 2010, pp. 673-680. doi:10.5650/jos.59.673 